\title{
Synthesis and Characterization of Polyamide by Interfacial Polycondensation of Dichloroformyl-Containing $\gamma$-Lactone with Hexamethylenediamine
}

\author{
Takao Kimura, ${ }^{*}$ Hideo Morimoto, ${ }^{\dagger}$ Eiji SASAKI, ${ }^{\dagger \dagger}$ \\ Kazunobu TanjI, and Motome Hamashima \\ Department of Applied Chemistry, Faculty of Engineering, Utsunomiya University, \\ Ishii-machi, Utsunomiya 321, Japan
}

(Received July 23, 1990)

\begin{abstract}
R^{*}, 4 S^{*}\right)$-4-chloroformyl-2-chloroformylmethyl-2,4-dimethyl-4-butanolide was prepared by the chemical transformation of $t$-butyl methacrylate dimer telomerized using bromotrichloromethane. The interfacial polycondensation of this acid dichloride with hexamethylenediamine was accompanined by a partial hydrolytic cleavage of the lactone ring and gave an unique 6,6-type polyamide containing both lactone rings and hydrophilic groups such as carboxyl- and hydroxyl-groups. To determine the optimal conditions for interfacial polycondensation, the influence of the following factors on yield, value of intrinsic viscosity, and ring-opening ratio of polyamide was studied: volume of phase solvent, molar ratio of diamine to acid dichloride, molar ratio of sodium hydroxide as a hydrogen chloride acceptor to acid dichloride, temperature of reaction, the kinds of hydrogen chloride acceptors and organic phases, and contribution of stirring. The resulting polyamide was highly soluble in methanol, which is a poor solvent for conventional polyamides. A transparent and flexible film prepared from the methanol solution by a casting technique had a glass transition temperature of $88^{\circ} \mathrm{C}$ and a water absorption of $c a .30 \%$ at $95 \%$ relative humidity. Furthermore, the carboxylato-containing polyamide modified by treatment with potassium hydroxide was very soluble in water.

KEY WORDS Bifunctional Lactone Monomer / Hexamethylenediamine /Interfacial Polycondensation / Lactone-Containing Polyamide / RingOpening / Carboxyl- and Hydroxyl-Containing Polyamide / MethanolSoluble Nylon / Hygroscopic Nylon /
\end{abstract}

In previous papers, ${ }^{1}$ we reported the free radical telomerization of methacrylate monomers using bromotrichloromethane (BTCM) as a telogen. The effects of the substituent in the ester group on the telomerization and characteristics of the resulting $n: 1$-[methacrylate monomer]:[BTCM] adducts were studied systematically.<smiles>[R20]C([R])(Br)C(C)(CC(C)(C)Cl)C(=O)O</smiles>

(I)

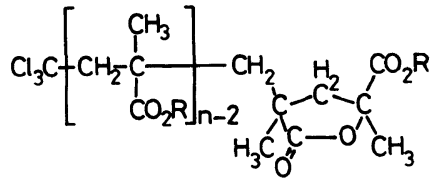

(II)
Linear (I) and cyclic adducts (II) were obtained as the products $(n \geqq 2)$. Cyclic adducts II have a $\gamma$-lactone skeleton, and II $(n=2)$ can be chemically induced into a bifunctional lactone monomer. The polycondensation of this monomer with hexamethylenediamine (HMDA) gives a 6,6-type polyamide having lactone rings, which can be converted into a hydrophilic 6,6-polyamide having carboxyland hydroxyl-groups by the hydrolytic cleavage of lactone rings.

The reactions between $\gamma$-lactones and amines to give 4-hydroxybutyramide derivatives are

\footnotetext{
* To whom all correspondence should be addressed.

† Present address: NAPP Systems (USA) Inc., 360, S. Pacific, San Marcos, CA 92069-3886, USA.

${ }_{\dagger}$ Present address: Chuo Co., Ltd., 13-2, Satsuki-machi, Kanuma 322, Japan.
} 
well known. ${ }^{2}$ Hayashi and Ueda et al. ${ }^{3,4}$ reported the synthesis of polyamide containing hydroxyl groups by the ring-opening polyaddition of 4,4'-disubstituted bis(4-butanolide) with HMDA. It is therefore presumed that the polycondensation of this monolactone monomer with HMDA may be accompanied by a ring-opening addition.

The present paper deals with a reasonable synthesis of bifunctional lactone monomer and interfacial polycondensation of this material with HMDA. The optimal conditions for interfacial polycondensation are discussed, and the structure and properties of the resulting polyamide are elucidated.

\section{EXPERIMENTAL}

\section{General Methods}

All melting points were measured on a Yamato MP-21 melting point apparatus and are uncorrected. IR spectra were obtained by using a JASCO REPORT-100 spectrophotometer. ${ }^{1} \mathrm{H}$ NMR spectra were determined with JEOL JNM-C-60-HL and Varian VXR300 spectrometers using $\mathrm{Me}_{4} \mathrm{Si}$ as an internal standard. ${ }^{13} \mathrm{C}$ NMR spectrum was taken on a Varian VXR-300 spectrometer. Mass spectra were recorded on a Hitachi M-80 spectrometer using a chemical ionization method at ionization energy of $20 \mathrm{eV}$. All isotope peaks resulting from chlorine atoms were satisfactorily detected in the mass spectra. The isotope peaks corresponding only to ${ }^{35} \mathrm{Cl}$ are described in this paper.

\section{Materials}

Commercial $t$-butyl methacrylate (TBMA), BTCM, and 2,2'-azobisisobutyronitrile were purified in a manner similar to that of the previous paper. ${ }^{1}$ HMDA was commercially obtained and purified by distillation under reduced pressure. Commercial carbon tetrachloride, tetrachloroethylene, chloroform, and benzene were dried over calcium hydride and distilled before use. Other reagents and solvents were commercially obtained and used without further purification.

\section{Synthesis of Difunctional Lactone Monomer}

$\left(2 R^{*}, 4 S^{*}\right)-4-t$-butoxycarbonyl-2,4-dimethyl2-(2,2,2-trichloroethyl)-4-butanolide (B-1). This lactone was obtained by a procedure similar that in the previous paper, ${ }^{1}$ and identical to an authentic sample: ${ }^{1}$ colorless needles (from ethyl acetate); mp $134.5-136^{\circ} \mathrm{C}$ (dec.); IR (KBr) 1775 (lactonic $\mathrm{C}=\mathrm{O}$ ) and $1750 \mathrm{~cm}^{-1}$ (esteric $\mathrm{C}=\mathrm{O}$ ); $\mathrm{MS} m / z$ (rel intensity) $345\left(\mathrm{QM}^{+}, 59\right)$, 311 (40), and $289(100) ;{ }^{1} \mathrm{H}$ NMR $(300 \mathrm{MHz}$, $\left.\mathrm{CDCl}_{3}\right) \delta=1.37\left(3 \mathrm{H}, \mathrm{s},-\mathrm{CH}_{3}\right), 1.51(9 \mathrm{H}$, $\mathrm{s},-t-\mathrm{Bu}), 1.66\left(3 \mathrm{H}, \mathrm{s},-\mathrm{CH}_{3}\right), 2.71(1 \mathrm{H}, \mathrm{d}$, $\left.J=13.9 \mathrm{~Hz},-\mathrm{CH}_{2}-\right), 2.81(1 \mathrm{H}, \mathrm{d}, J=13.9 \mathrm{~Hz}$, $\left.-\mathrm{CH}_{2}-\right), 3.15\left(1 \mathrm{H}, \mathrm{d}, J=15.6 \mathrm{~Hz},-\mathrm{CH}_{2}-\right)$, and $3.36\left(1 \mathrm{H}, \mathrm{d}, J=15.6 \mathrm{~Hz},-\mathrm{CH}_{2}-\right) .{ }^{13} \mathrm{C} \mathrm{NMR}$ $\left(75 \mathrm{MHz}, \mathrm{CDCl}_{3}\right) \quad \delta=24.38,25.71,27.69$, 43.16, 44.73, 59.79, 81.45, 83.06, 96.27, 171.30, and 178.47. Anal. Found: C, 44.97\%; H, $5.77 \%$. Calcd for $\mathrm{C}_{13} \mathrm{H}_{19} \mathrm{O}_{4} \mathrm{Cl}_{3}: \mathrm{C}, 45.17 \%$; $\mathrm{H}, 5.54 \%$.

$\left(2 R^{*}, 4 S^{*}\right)-4-$ carboxy-2,4-dimethyl-2-(2,2,2trichloroethyl)-4-butanolide (B-2). This monocarboxylic acid was obtained by a method described elsewhere, ${ }^{1}$ and identical to an authentic sample: ${ }^{1}$ colorless columns (from ethyl acetate); $\mathrm{mp} 177-179^{\circ} \mathrm{C}(\mathrm{dec}$ ); IR (KBr) $3000(\mathrm{OH}), 1780$ (lactonic $\mathrm{C}=\mathrm{O}$ ), and $1720 \mathrm{~cm}^{-1}$ (carboxylic $\mathrm{C}=\mathrm{O}$ ); $\mathrm{MS} m / z$ (rel intensity) $289\left(\mathrm{QM}^{+}, 100\right)$ and $253(8) ;{ }^{1} \mathrm{H}$ NMR $\left(60 \mathrm{MHz}, \mathrm{DMSO}-d_{6}\right) \delta=1.30(3 \mathrm{H}, \mathrm{s}$, $\left.-\mathrm{CH}_{3}\right), 1.62\left(3 \mathrm{H}, \mathrm{s},-\mathrm{CH}_{3}\right), 2.72\left(2 \mathrm{H}, \mathrm{s},-\mathrm{CH}_{2}-\right)$, $3.13\left(1 \mathrm{H}, \mathrm{d}, J=15.0 \mathrm{~Hz},-\mathrm{CH}_{2}-\right)$, and $3.48(1 \mathrm{H}$, d, $\left.J=15.0 \mathrm{~Hz},-\mathrm{CH}_{2}-\right)$. Anal. Found: C, $37.21 \% ; \mathrm{H}, 3.60 \%$. Calcd for $\mathrm{C}_{9} \mathrm{H}_{11} \mathrm{O}_{4} \mathrm{Cl}_{3}: \mathrm{C}$, $37.33 \% ; \mathrm{H}, 3.83 \%$.

$\left(2 R^{*}, 4 S^{*}\right)-4-c a r b o x y-2$-carboxymethyl-2,4dimethyl-4-butanolide (B-3). A solution of B-2 $(10 \mathrm{~g})$ in $85 \%$ phosphoric acid $(100 \mathrm{ml})$ was heated at $150^{\circ} \mathrm{C}$ for $72 \mathrm{~h}$. The reaction mixture was poured into $500 \mathrm{ml}$ of cold water and allowed to stand for a few days upon cooling. The resulting precipitate afforded $6.7 \mathrm{~g}(90 \%)$ of B-3: colorless columns (from ethyl acetate); 


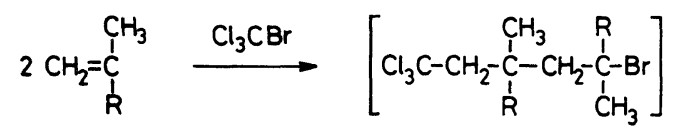

$\mathrm{R}=\mathrm{CO}_{2} \mathrm{C}\left(\mathrm{CH}_{3}\right)_{3}$ : TBMA
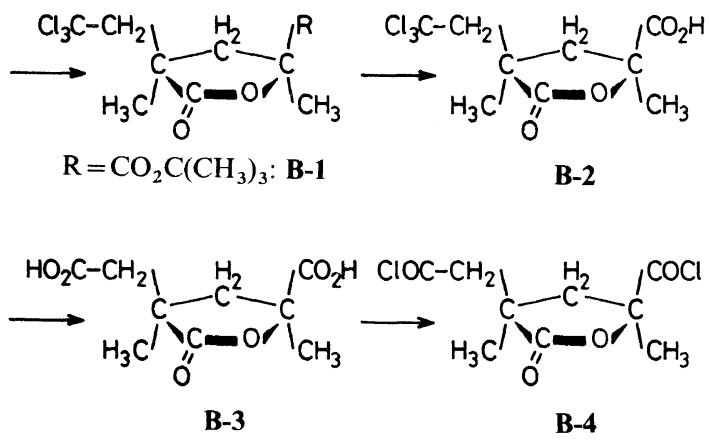

Scheme 1. Synthesis of the bifunctional lactone monomer.

$\mathrm{mp} 143-145^{\circ} \mathrm{C}$ (dec.); IR (KBr) $3000(\mathrm{OH})$, 1760 (lactonic $\mathrm{C}=\mathrm{O}$ ), and $1730,1710 \mathrm{~cm}^{-1}$ (carboxylic $\mathrm{C}=\mathrm{O}$ ); MS $m / z$ (rel intensity) 217 $\left(\mathrm{QM}^{+}, 91\right), 199$ (61), and 171 (31); ${ }^{1} \mathrm{H}$ NMR $\left(60 \mathrm{MHz}, \quad 4: 1-\mathrm{CDCl}_{3}: \mathrm{DMSO}-d_{6}\right) \quad \delta=1.27$ $\left(3 \mathrm{H}, \mathrm{s},-\mathrm{CH}_{3}\right), 1.67\left(3 \mathrm{H}, \mathrm{s},-\mathrm{CH}_{3}\right), 2.31(1 \mathrm{H}$, $\left.\mathrm{d}, J=14.4 \mathrm{~Hz},-\mathrm{CH}_{2}-\right), 2.44(1 \mathrm{H}, \mathrm{d}, J=17.4$ $\left.\mathrm{Hz},-\mathrm{CH}_{2}-\right), 2.59\left(1 \mathrm{H}, \mathrm{d}, J=14.4 \mathrm{~Hz},-\mathrm{CH}_{2}-\right)$, and $2.79\left(1 \mathrm{H}, \mathrm{d}, J=17.4 \mathrm{~Hz},-\mathrm{CH}_{2}^{-}\right)$. Anal. Found: $\mathrm{C}, 48.55 \% ; \mathrm{H}, 5.54 \%$. Calcd for $\mathrm{C}_{9} \mathrm{H}_{12} \mathrm{O}_{6}$ : C, $50.00 \%$; H, 5.59\%.

$\left(2 R^{*}, 4 S^{*}\right)$-4-chloroformyl-2-chloroformylmethyl-2,4-dimethyl-4-butanolide (B-4). A solution of B-3 $(6 \mathrm{~g})$ in thionyl chloride $(10 \mathrm{ml})$ was gently heated at $50-60^{\circ} \mathrm{C}$ for $1.5 \mathrm{~h}$, followed by refluxing for $2 \mathrm{~h}$. After evaporating to dryness, the residue was purified by recrystallization to give $4.9 \mathrm{~g}(70 \%)$ of $\mathbf{B}-4$ : colorless needles (from carbon tetrachloride); $\mathrm{mp} 73-74.5^{\circ} \mathrm{C}$; IR $(\mathrm{KBr}) 1785 \mathrm{~cm}^{-1}(\mathrm{C}=\mathrm{O})$; MS $m / z$ (rel intensity) $253\left(\mathrm{QM}^{+}, 78\right), 217$ (100), and 189 (76); ${ }^{1} \mathrm{H}$ NMR $\left(60 \mathrm{MHz}, \mathrm{CCl}_{4}\right)$ $\delta=1.27\left(3 \mathrm{H}, \mathrm{s},-\mathrm{CH}_{3}\right), 1.79\left(3 \mathrm{H}, \mathrm{s},-\mathrm{CH}_{3}\right), 2.35$ $\left(1 \mathrm{H}, \mathrm{d}, J=13.8 \mathrm{~Hz},-\mathrm{CH}_{2}-\right), 2.77(1 \mathrm{H}, \mathrm{d}$, $\left.J=13.8 \mathrm{~Hz},-\mathrm{CH}_{2}-\right)$, and $3.28\left(2 \mathrm{H}, \mathrm{s},-\mathrm{CH}_{2}-\right)$. After purification, this unstable acid dichloride was immediately used for interfacial poly- condensation.

\section{Interfacial Polycondensation}

A mixed solution of desired amounts of HMDA and hydrogen chloride acceptor in a prescribed amount of water was poured onto a solution of B-4 $(3 \mathrm{mmol})$ in the same amount of organic solvent. In the case of a standing method, the resulting polyamide was drawn up as a string. On the other hand, in the case of a stirring method, the reaction solution was mixed by using a homogenizer $\left(1 \times 10^{4} \mathrm{rpm}\right)$ for $5 \mathrm{~min}$. The product was collected, washed with water, and dried up at $60^{\circ} \mathrm{C}$ under reduced pressure. The polyamide, if necessary, was purified by precipitation in a combination of methanol as the solvent and water as the precipitant: colorless, transparent, and flexible film (cast from the methanol solution); IR (film) $3340(\mathrm{OH}$ and $\mathrm{NH}), 1780$ (lactonic $\mathrm{C}=\mathrm{O}), 1700$ (carboxylic $\mathrm{C}=\mathrm{O}$ ), and 1650, $1530 \mathrm{~cm}^{-1}$ (CONH). Anal. Found: C, 60.07\%; H, 8.09\%; $\mathrm{N}, 9.42 \%$. Calcd for $\mathrm{C}_{15} \mathrm{H}_{24.7} \mathrm{~N}_{2} \mathrm{O}_{4.35}$ (as ring-opening ratio, $35 \%$ ): $\mathrm{C}, 59.52 \% ; \mathrm{H}$, $8.23 \% ; \mathrm{N}, 9.26 \%$.

\section{Chemical Treatment of Polyamide by $\mathrm{KOH}$}

To a solution of polyamide $(0.2 \mathrm{~g})$ in methanol $(15 \mathrm{ml})$, a $0.6 \% \mathrm{KOH}$ aqueous solution $(5 \mathrm{ml})$ was added. After evaporating to dryness, the residue was chromatographed to remove the excess $\mathrm{KOH}$ using Sephadex G-10 as the packing material and water as the eluent. The polymer weighed $c a .0 .2 \mathrm{~g}$ and the IR spectrum of film cast from the methanol solution showed a new absorption at 1580 $\mathrm{cm}^{-1}\left(\mathrm{COO}^{-}\right)$.

\section{Characterization of Polyamide}

The intrinsic viscosity $[\eta]$ in $90 \%$ formic acid was measured with a Ubbelohde viscometer at $25^{\circ} \mathrm{C}$. Measurement of the DSC curve was taken on a Rigaku Denki Thermoflex DSC8230 at a heating rate of $20^{\circ} \mathrm{Cmin}^{-1}$ in a nitrogen atmosphere. The ring-opening ratio was determined from absorbance $(A)$ on IR 
spectrum: $A_{1700} /\left(A_{1780}+A_{1700}\right) \times 100 \%$. The water absorption was calculated from the following equation: ( $\left.W_{\text {wet }}-W_{\text {dry }}\right) / W_{\text {wet }} \times$ $100 \%$, where $W_{\text {wet }}$ is the weight of swollen polyamide at $95 \%$ RH (relative humidity) for $24 \mathrm{~h}$ and $W_{\text {dry }}$ is the weight of the dry polyamide.

\section{RESULTS AND DISCUSSION}

\section{Synthesis of the Bifunctional Lactone Monomer}

Scheme 1 shows the synthetic route of acid dichloride having a $\gamma$-lactone ring. Acid dichloride B-4 was derived from the cyclic TBMA dimer B-1, which was obtained in the radical telomerization to TBMA using BTCM as a telogen. The structures of B-4 and its precursors were confirmed by IR, MS, NMR spectra, or elemental analysis data.

\section{Synthesis of Polyamide}

The 6,6-type polyamide having lactone rings and hydrophilic groups such as carboxyl- and hydroxyl-groups was prepared by interfacial polycondensation of B-4 with HMDA. To determine the optimal conditions for interfacial polycondensation, the influence of the following factors on yield, $[\eta]$, and ring-opening ratio of polyamide was studied: volume of phase solvent, molar ratio of HMDA to B-4, molar ratio of sodium hydroxide as a hydrogen chloride acceptor to B-4, temperature of reaction, the kinds of hydrogen chloride acceptors and organic phases, and contribution of stirring. After determining the initial reaction conditions, that is, the aqueous-toorganic phase ratio, $1: 1$; hydrogen chloride acceptor, sodium hydroxide; organic phase, carbon tetrachloride; molar ratio of the reagents, HMDA : B-4: $\mathrm{NaOH}=1: 1: 2$; reaction temperature, r.t., the effect of the volume of phase solvent on results of interfacial polycondensation was examined under standing. As shown in Figure 1, the polyamide obtained in $10 \mathrm{ml}$ of phase solvent had the lowest value of [ $\eta]$. In $20 \mathrm{ml}$ and $40 \mathrm{ml}$ of phase

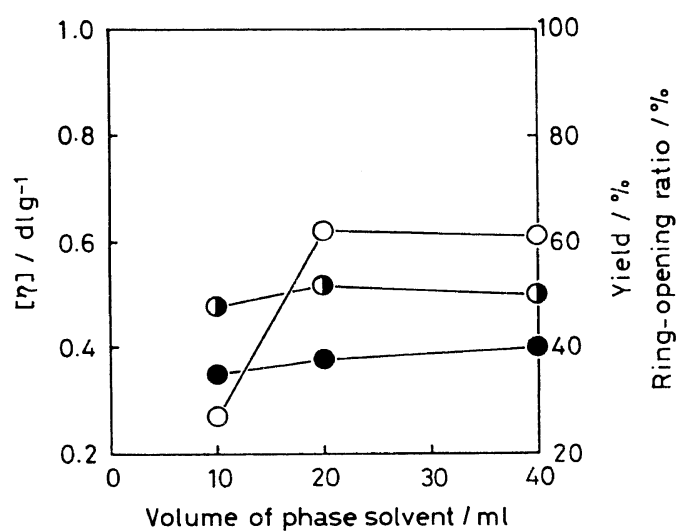

Figure 1. Effect of volume of phase solvent on intrinsic viscosity (--O-), yield (-- - ) , and ring-opening ratio (- - ) of polyamide from HMDA and B-4: organic phase, B-4 $(3 \mathrm{mmol})$ in $\mathrm{CCl}_{4}$; water phase, HMDA ( $3 \mathrm{mmol})$ and $\mathrm{NaOH}(6 \mathrm{mmol})$ in $\mathrm{H}_{2} \mathrm{O}$; r.t.; standing method.

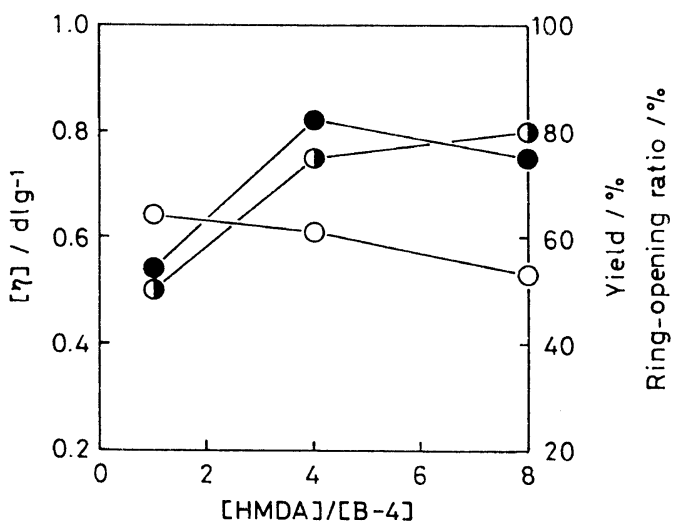

Figure 2. Effect of molar ratio of HMDA to B-4 on intrinsic viscosity (-O-), yield (- - ), and ringopening ratio (-O-) of polyamide from HMDA and B-4: organic phase, B-4 $(3 \mathrm{mmol})$ in $\mathrm{CCl}_{4}(20 \mathrm{ml})$; water phase, $\mathrm{HMDA}$ and $\mathrm{NaOH}(6 \mathrm{mmol})$ in $\mathrm{H}_{2} \mathrm{O}(20 \mathrm{ml})$; r.t.; standing method.

solvent, the dilution effect of solvent on yield, $[\eta]$, and the ring-opening ratio of the polyamide was not observed clearly.

The molar excess effect of HMDA to B-4 in $20 \mathrm{ml}$ of phase solvent was examined in a range of $1: 1-8: 1$ as illustrated in Figure 2. Under a stoichiometric molar ratio, that is, HMDA : B-4 $=1: 1$, the resulting polyamide had favorable $[\eta]$, which decreased with increase in the 


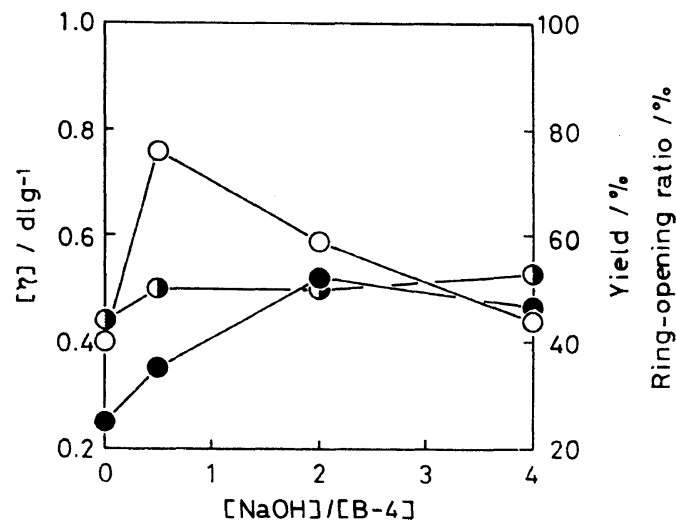

Figure 3. Effect of molar ratio of $\mathrm{NaOH}$ to B-4 on intrinsic viscosity (-O-), yield (- -$)$, and ringopening ratio (- - ) of polyamide from HMDA and B-4: organic phase, B-4 $(3 \mathrm{mmol})$ in $\mathrm{CCl}_{4}(20 \mathrm{ml})$; water phase, $\mathrm{HMDA}(3 \mathrm{mmol})$ and $\mathrm{NaOH}$ in $\mathrm{H}_{2} \mathrm{O}(20 \mathrm{ml})$; r.t.; standing method.

molar ratio. On the other hand, the polyamide obtained in HMDA : B-4 $=4: 1$ had the best yield, and the ring-opening ratio of polyamide obtained caused increase with molar ratio. It is considered that the excess of HMDA promotes the hydrolytic cleavage of the lactone ring.

Under the molar ratio of HMDA : B-4 $=1: 1$, the effect of the molar ratio of sodium hydroxide as a hydrogen chloride acceptor to B-4 on the results of the polyamide was examined at a ratio of $0: 1-4: 1$. As Figure 3 shows, the highest value of $[\eta]$ of polyamide was achieved in $\mathrm{NaOH}: \mathbf{B}-4=0.5: 1$, whereas the best yield at a stoichiometric molar ratio, that is, $\mathrm{NaOH}: \mathbf{B}-\mathbf{4}=2: 1$. Furthermore, the polyamide, which has the lowest values of yield and $[\eta]$, was also obtained in the absence of sodium hydroxide, that is, $\mathrm{NaOH}: \mathbf{B}-4=0: 1$. However, the ring-opening ratio of polyamide was almost constant at $40-50 \%$ regardless of the concentration of sodium hydroxide.

Figure 4 shows the effect of temperature on the results of interfacial polycondensation at a molar ratio of HMDA :B-4: $\mathrm{NaOH}=$ $1: 1: 0.5$. A significant difference was not observed in the range of $-10-30^{\circ} \mathrm{C}$.

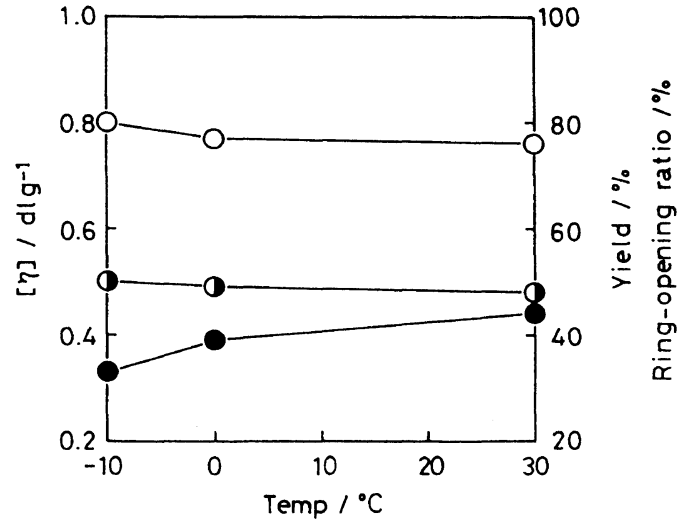

Figure 4. Effect of reaction temperature on intrinsic viscosity (-O-), yield (- - - ), and ring-opening ratio (-O) of polyamide from HMDA and B-4: organic phase, B-4 (3 mmol) in $\mathrm{CCl}_{4}(20 \mathrm{ml})$; water phase, HMDA ( $3 \mathrm{mmol})$ and $\mathrm{NaOH}(1.5 \mathrm{mmol})$ in $\mathrm{H}_{2} \mathrm{O}(20 \mathrm{ml})$; standing method.

Table I. Effect of hydrogen chloride acceptor on interfacial polycondensation ${ }^{\mathrm{a}}$

\begin{tabular}{|c|c|c|c|}
\hline \multirow{2}{*}{$\begin{array}{l}\text { Hydrogen chloride } \\
\text { acceptor }\end{array}$} & {$[\eta]$} & Yield & \multirow{2}{*}{$\begin{array}{l}\text { Ring-opening } \\
\text { ratio/\% }\end{array}$} \\
\hline & $\mathrm{dl} \mathrm{g}^{-1}$ & $\%$ & \\
\hline $\mathrm{NaOH}$ & 0.59 & 52 & 50 \\
\hline $\mathrm{Na}_{2} \mathrm{CO}_{3}$ & 0.39 & 64 & 51 \\
\hline$\left(\mathrm{C}_{2} \mathrm{H}_{5}\right)_{3} \mathrm{~N}$ & 0.29 & 30 & 36 \\
\hline
\end{tabular}

a Organic phase, B-4 $(3 \mathrm{mmol})$ in $\mathrm{CCl}_{4}(20 \mathrm{ml})$; water phase, HMDA $(3 \mathrm{mmol})$ and hydrogen chloride acceptor $(6 \mathrm{mmol})$ in $\mathrm{H}_{2} \mathrm{O}(20 \mathrm{ml})$; r.t.; standing method.

Table I shows the effect of hydrogen chloride acceptor on the results of interfacial polycondensation under the stoichiometric molar ratio of reagents. Sodium hydroxide, sodium carbonate, and triethylamine were used as the hydrogen chloride acceptors. Though the $[\eta]$ values of polyamide obtained with both sodium carbonate and triethylamine were lower than that of polyamide with sodium hydroxide, ring-opening of polyamide was observed, regardless of the kind of hydrogen chloride acceptor.

The four kinds of solvents, that is, carbon tetrachloride, tetrachloroethylene, chloroform, 
Table II. Effect of the organic phase on interfacial polycondensation ${ }^{\mathrm{a}}$

\begin{tabular}{lcccc}
\hline Organic phase & {$[\eta]$} & & Yield & $\begin{array}{c}\text { Ring-opening } \\
\text { ratio/\% }\end{array}$ \\
\cline { 2 - 2 } \cline { 5 - 5 } & $\mathrm{dlg} \mathrm{g}^{-1}$ & & $\%$ & \\
\hline $\mathrm{CCl}_{4}$ & 0.76 & & 35 & 50 \\
$\mathrm{Cl}_{2} \mathrm{C}=\mathrm{CCl}_{2}$ & 0.78 & & 35 & 40 \\
$\mathrm{CHCl}_{3}$ & - & & - & - \\
$\mathrm{PhH}$ & 0.84 & & 15 & 47 \\
\hline
\end{tabular}

a Organic phase, B-4 $(3 \mathrm{mmol})$ in organic solvent $(20 \mathrm{ml})$; water phase, HMDA $(3 \mathrm{mmol})$ and $\mathrm{NaOH}(1.5 \mathrm{mmol})$ in $\mathrm{H}_{2} \mathrm{O}(20 \mathrm{ml})$; r.t.; standing method.

Table III. Contribution of stirring on interfacial polycondensation ${ }^{a}$

\begin{tabular}{|c|c|c|c|c|}
\hline \multirow{2}{*}{ Method } & \multirow{2}{*}{$\begin{array}{l}\text { Organic } \\
\text { phase }\end{array}$} & {$[\eta]$} & Yield & \multirow{2}{*}{$\begin{array}{l}\text { Ring-opening } \\
\text { ratio/\% }\end{array}$} \\
\hline & & $\mathrm{dl} \mathrm{g}^{-1}$ & $\%$ & \\
\hline \multirow{2}{*}{$\begin{array}{l}\text { Stirring } \\
\text { Standing }\end{array}$} & \multirow{2}{*}{$\mathrm{PhH}$} & 0.94 & 46 & 39 \\
\hline & & 0.68 & 7 & 46 \\
\hline \multirow{2}{*}{$\begin{array}{l}\text { Stirring } \\
\text { Standing }\end{array}$} & \multirow{2}{*}{$\mathrm{CCl}_{4}$} & 0.60 & 73 & 35 \\
\hline & & 0.50 & 23 & 40 \\
\hline
\end{tabular}

a Organic phase, B-4 (3 mmol) in organic solvent $(20 \mathrm{ml})$; water phase, $\mathrm{HMDA}(3 \mathrm{mmol})$ and $\mathrm{NaOH}(1.5 \mathrm{mmol})$ in $\mathrm{H}_{2} \mathrm{O}(20 \mathrm{ml})$; r.t.

and benzene were used as the organic phase. As shown in Table II, the polyamide obtained with benzene indicated the highest value of $[\eta]$ but low yield. The preferable yield was achieved with both carbon tetrachloride and tetrachloroethylene. However, the interfacial polycondensation with chloroform showed an exothermic change accompanied by a ready cloudiness in organic phase, but there was no yield of the polyamide. It is anticipated that a faster diffusion of HMDA into the chloroform layer facilitates the hydrolysis of unstable B-4 into dicarboxylic acid B-3.

Table III shows the contribution of stirring on the results of interfacial polycondensation. Irrespective of the kind of organic phase, the value of $[\eta]$ and yield of polyamide prepared under stirring were superior to those of polyamide under standing.
View on Cleavage Behavior of Lactone Ring

The ring-opening addition reaction of dicarboxyl lactone monomer B-3 $(5 \mathrm{mmol})$ with benzylamine $(15 \mathrm{mmol})$ was attempted as a model according to the method of Ueda et al. ${ }^{4}$ At reflux in methanol $(15 \mathrm{ml})$ for 4 days, the expected reaction did not proceed although the 2: 1-benzylamine: B-3 salt was considerably formed. Under similar conditions, the ringopening additions of B-3 with HMDA and $\mathrm{KOH}$, as well as benzylamine, were not observed. It is therefore considered that $\alpha, \alpha, \gamma, \gamma$-tetrasubstituted $\gamma$-lactone such as B-3 and B-4 is much less subject to ring-opening addition with amines than $\gamma$-monosubstituted ones studied by Ueda et al. ${ }^{4}$

However, the interfacial polycondensation of B-4 with HMDA was accompanied by a readily observable ring-opening of lactone moiety. As can be seen from Figures 2 and 3, the cleavage of the lactone ring occurred even in the absence of sodium hydroxide. Steric distortion increasing with length of the main chain of polyamide perhaps causes the lactone ring to be cleaved spontaneously.

\section{Structure and Characterization of Polyamide}

The IR spectrum of polyamide prepared from HMDA and B-4 exhibited carbonyl absorptions owing to lactone ring and amide linkage at 1780,1660 , and $1530 \mathrm{~cm}^{-1}$, as shown in Figure 5. In addition, there appeared new absorption bands at 3340 and $1700 \mathrm{~cm}^{-1}$ due to carboxyl- and hydroxyl-groups formed in the hydrolytic cleavage of lactone ring.

On the basis of good agreement of the calculated and found analytical data and IR spectrum, the structure of polyamide obtained is proposed as illustrated in Scheme 2 .

The resulting polyamide is characterized by the property of dissolving freely in methanol, which is a poor solvent for conventional polyamides. For example, the polyamide having $[\eta]$ of 0.94 and ring-opening ratio of $39 \%$ was soluble in methanol at concentration of about 7 (r.t.) and $11 \mathrm{~g} \mathrm{dl}^{-1}\left(60^{\circ} \mathrm{C}\right)$, 


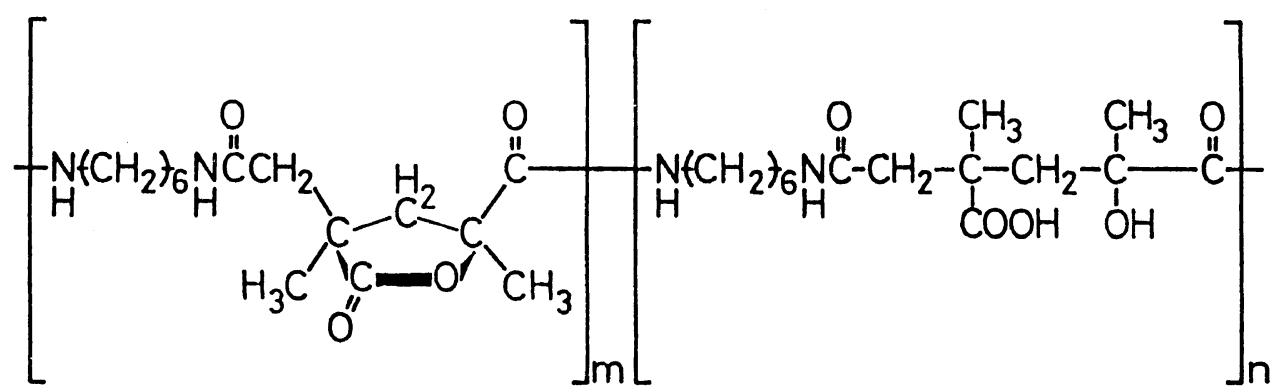

Scheme 2. Structure of the polyamide from HMDA and B-4.

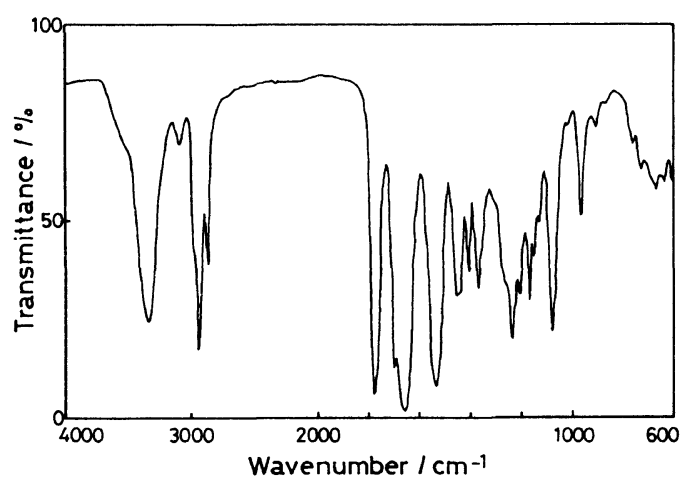

Figure 5. IR spectrum of polyamide from HMDA and B-4.

respectively. A transparent and flexible film cast from the methanol solution had a glass transition temperature of $88^{\circ} \mathrm{C}$ and a water absorption of about $30 \%$ at $95 \%$ RH. Furthermore, the carboxylato-containing polyamide modified by treatment with $\mathrm{KOH}$ was highly soluble in water $\left(25 \mathrm{~g} \mathrm{dl}^{-1}\right.$ at $\left.60^{\circ} \mathrm{C}\right)$. These features of polyamide are due to holding lactone rings and hydrophilic groups such as carboxyl- and hydroxyl-groups.
Acknowledgments. The authors wish to thank Mr. Tetsuji Kodaira of GE Plastics Japan Ltd. for the measurement of DSC curve of polyamide. We are also grateful to Prof. Masahiro Minabe, Dr. Motohiro Tsubota, and Dr. Kazuo Haga of Utsunomiya University for their valuable discussion.

\section{REFERENCES}

1. For previous papers on telomerization of methacrylates with bromotrichloromethane, see: (a) $\mathrm{T}$. Kimura, T. Kodaira, and M. Hamashima, Polym. J., 15, 293 (1983). (b) T. Kimura and M. Hamashima, ibid., 18, 21 (1986). (c) T. Kimura, I. Nakanishi, and M. Hamashima, ibid., 18, 689 (1986). (d) T. Kimura, H. Tasaka, and M. Hamashima, ibid., 19, 305 (1987). (e) T. Kimura, T. Yoshimura, H. Morimoto, and M. Hamashima, ibid., 19, 1165 (1987). (f) T. Kimura and M. Hamashima, ibid., 20, 45 (1988).

2. N. H. Cromwell and K. E. Cook, J. Am. Chem. Soc., 80, 4573 (1958).

3. I. Hayashi, S. Takakura, and Y. Hachihama, Kogyo Kagaku Zasshi, 60, 646 (1957).

4. M. Ueda, M. Yabuuchi, and Y. Imai, J. Polym. Sci., Polym. Chem. Ed., 15, 323 (1977). 